\title{
Design and Testing of High Current, High Voltage Hexapolar Flexible Cables For Pulsed Power Applications
}

J. H. Price, D. A. Badger \& R. A. Lee.

The University of Texas at Austin Texas

Center for Electromechanics

Balcones Research Center Building 133

Austin, Texas 78712

Abstract: Under Defense Advanced Research Projects Agency (DARPA) and U.S. Army sponsorship, the Center for Electromechanics has designed and is constructing highly flexible, high current and voltage, magnetically compensated (hexapolar) cables and cable terminations as component interconnect buswork for a stand-alone, Compulsator-driven electromagnetic (EM) gun system.

Flexible cables under development are rated at $300 \mathrm{kA}$ peak current and peak voltage of $15 \mathrm{kV}$. Cable construction in this configuration provides several advantages; high flexibility, outstanding insulation integrity, ease in termination, and large conductor net cross sectional area (fig. 1). Standardized modular cable terminations are also being developed featuring compact construction, small footprint, a unique single-bolt (per polarity) high contact area/pressure electrical terminal, and electromagnetically self supporting high voltage insulated casing. The cable termination mates to a simply machined receptacle.

Presented are cable and termination design criteria, cable parallel operation simulations and preliminary performance test data collected. A list of vendors capable of manufacturing the cables and terminations is also included.

\section{BACKGROUND}

The Center for Electromechanics has designed and is constructing a stand-alone, repetitively fired, Compulsator-driven electromagnetic (EM) gun system $[1,2]$ capable of firing nine projectile launch packages to velocities between 2.5 and $4.0 \mathrm{~km} / \mathrm{s}$, muzzle kinetic energies of $9 \mathrm{MJ}$, at a rate of one shot every $20 \mathrm{~s}$. Major system components include power generator (Compulsator), EM gun, circuit switching components, Compulsator/switch/gun interconnect buswork, auxiliary systems, data acquisition and control system, and component mounting/support structure. This system is to be tested in an open range environment.

Electrical performance ratings for the Compulsator are a peak output current of $3.2 \mathrm{MA}$, peak voltage of $5.8 \mathrm{kV}$, and a peak power of $16 \mathrm{GW}$. In addition, the Compulsator utilizes a selfexcitation circuit that operates at $41.5 \mathrm{kA}, 15 \mathrm{kV}$, and a peak power of $600 \mathrm{MW}$. Operation of the system in an open range with extreme environmental conditions as well as high current/voltage ratings of the components have resulted in stringent design constraints being placed on the electrical buswork used to interconnect the various high power circuit devices. Further buswork design constraints result from EM gun recoil and limited package size.

\section{FLEXIBLE BUSWORK DESIGN CONSIDERATIONS}

Design and construction of a multimillion amp bus which connects a pulsed power supply to an EM gun requires careful consideration of many performance, operational, environmental and maintenance design constraints. Recent experience at CEM-UT [3] illustrated that several seemingly innocuous details of a rigid 3.2 MA

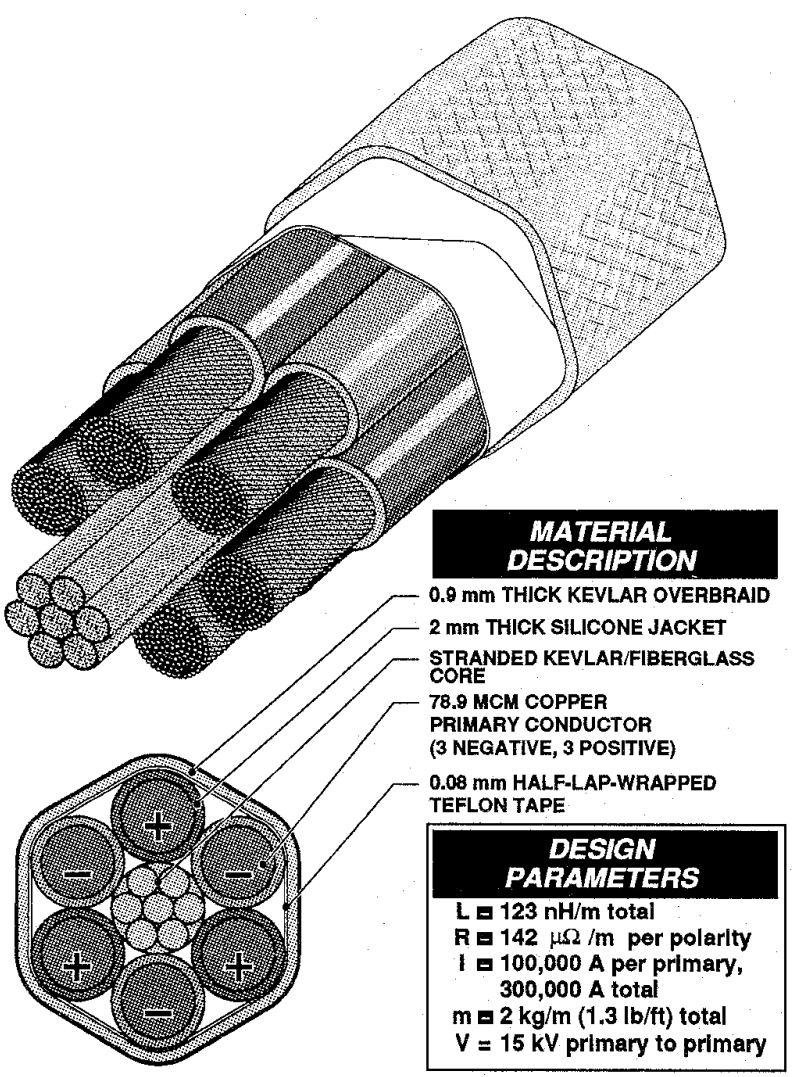

Figure 1. Hexapolar Flexible Cable: construction and performance parameters

laminated plate bus design were, after testing commenced, found to be of critical importance. The areas identified were:

- positive control of electrical contact area and clamping pressure at bus joints and terminations

- mechanical strain relief of bus joints and terminations while subjected to EM repulsion and bus flexure loads

- maintenance of insulation integrity at intermediate lap joints in insulation materials

- prevention of polarity-to-polarity arcing at bus joints and terminations with line-of-sight insulation barriers

- selective control of current distribution in individual bus conductors with termination inductance design

In addition to these considerations, buswork design constraints imposed by the field based system included provision for recoiling motion of the EM gun and complex routing path geometry as well as tolerance of exposure to environmental conditions such as sunlight, condensation, rain, extreme ambient temperature variations and wind-born particulate contaminates. Furthermore, current 
sharing performance of the modular, 3.2 MA, solid-state, thyristorcontrolled main circuit closing switch of the Compulsator-EM gun circuit [4] could be enhanced by using the inductance of a single cable connected to an individual switch module to force uniform current sharing between the 48 switch modules in the system.

After consideration of these constraints, the following buswork design parameters were əstablished:

- 48 parallel cables, one per switch module

- total peak operating current of 3.2 MA, 66.7 kA per cable

- $15 \mathrm{kV}$ peak operating voltage (for excitation circuit duty)

- $100 \mathrm{nH}$ total circuit inductance

- $50 \mu \Omega$ total circuit resistance

- $0.25 \mathrm{~m}$ gun recoil allowance

- $7.7 \mathrm{~m}$ cable length

- conductor temperature rise not to exceed $200^{\circ} \mathrm{C}$

- $29.4 \times 10^{9} \mathrm{~A}^{2} \mathrm{~s}$ total action per shot for, 9 shots $12.8 \times 10^{6} A^{2} s$ action per shot per cable, 9 shots

- $39.1 \times 10^{9} \mathrm{~A}^{2} \mathrm{~s}$ total action per shot for, 2 shots $17.0 \times 10^{6} \mathrm{~A}^{2} \mathrm{~s}$ action per shot per cable, 2 shots

\section{FLEXIBLE CABLE SELECTION}

Primarily due to the gun recoil requirements, a rigid laminated plate bus was eliminated as a design candidate early in the process. Utilization of a number of flexible cables to construct the bus was an obvious choice in the design process but commercially available cables that were rated at both the system operating voltage and a reasonable incremental fraction of the system operating current were generally unavailable. Of the numerous commercially available cable designs considered, two low inductance cable configurations were found to be of particular interest; a FLEX LO-6X 500 MCM Kickless Cable $(B)$ [5] and a high voltage/current coaxial cable under development by the Air Force Armament Laboratory, Electromagnetic Launcher Technology Branch (AFATALSSAH) [6].

The Kickless cable is typically employed by the automotive industry in robotic welding applications and is constructed by helically winding six uninsulated stranded copper primary conductors of alternating polarity (hexapolar) about a central axis where each is supported within a six-point star shaped extruded rubber separator (insulator). This assembly is contained within a reinforced rubber hose which provides mechanical support and allows for active water cooling. Each of the three conductors of like polarity are connected at the cable termination to a single solid copper connector. As constructed, the Kickless cable minimizes cable inductance and therefore EM repulsion loads experienced during a current pulse. Unlike coaxial cables, helical winding of the conductors in the Kickless design reduces the tendency of the cable to straighten out under EM loading while simultaneously cable flexibility is increased. Unfortunately, the commercially available version of the cable is only rated to $100 \mathrm{~V}$ and $12,000 \mathrm{~A}$ (continuous RMS).

The AFATAL/SAH coaxial cables were attractive as they were designed for operation in a similar environment as the one under study, and had undergone a thorough development and testing cycle wherein $6.5 \mathrm{kV}$ voltage and $273 \mathrm{kA}$ current operation had been demonstrated [6]. Unfortunately, at a nominal "round-trip" resistance of $428 \mu \Omega / \mathrm{m}(247 \mu \Omega / \mathrm{m}$ inner polarity, $181 \mu \Omega / \mathrm{m}$ outer polarity), 48 cables would represent a total circuit resistance of $68.7 \mu \Omega, \sim 50 \%$ higher than we desired. The manufacturer of the cable, Specialty Cable Corporation, was contacted to determine if a larger (lower resistance) cable of similar capabilities could be manufactured but were informed that limits on insulation extrusion press capacities prevented an increase in overall cable diameter.

A developmental variant of the hexapolar configuration was proposed in order to overcome the limitations on the maximum outside assembly diameter found in the AFATAL/SAH coaxial cables while providing higher voltage and current operating capabilities than the Kickless cable although maintaining the advantages of the configuration. By using high voltage insulated primary conductors in the design, operating voltage requirements could be met and utilization of a high strength braided fiber over-wrap, magnetic loads could be managed. After numerous design iterations and consultations with several cable manufacturers as to their fabrication capabilities, construction parameters for a hexapolar design were established. Surprisingly, although the resulting hexapolar cable that satisfied the design criteria discussed earlier, its fabrication cost was found to be approximately $30 \%$ less than the AFATAL/SAH design.

\section{FLEXIBLE CABLE DESIGN}

Design allowables for an individual cable were driven by the main discharge circuit design allowables, namely resistance, inductance, peak current, peak action, and maximum temperature rise. Maximum cable length was estimated at $7.7 \mathrm{~m}$ to connect the compulsator-switch-gun circuit. To compensate for termination bulk and contact resistance, the allowable total cable resistance was limited to $90 \%$ of the main circuit. For 48 cables, each $7.7 \mathrm{~m}$ long, this resulted in a cable resistance design goal of $45 \mu \Omega / \mathrm{m}$ per polarity. Correspondingly, the maximum cable inductance was limited to $300 \mathrm{nH} / \mathrm{m}$. After consulting with cable manufacturers about recommended insulation materials and conductor stranding, a nominal cable geometry was defined with $10.7 \mathrm{~mm}$ nominal diameter primary conductors (net copper cross sectional area of $0.404 \mathrm{~cm}^{2}$ per primary, $1.21 \mathrm{~cm}^{2}$ per polarity) equally spaced about a central axis at a radius of $14.7 \mathrm{~mm}$. Single-shot conductor temperature rise at 12.8 and $17.0 \times 10^{6} \mathrm{~A}^{2} \mathrm{~s}$ was calculated to be 4.4 and $5.8^{\circ} \mathrm{C}$ [6, eq. 2] respectively. For the nine and two shot cases and adiabatic conditions, maximum temperature rise was predicted to be 39.6 and $11.7^{\circ} \mathrm{C}$, respectively. To fully utilize the thermal capacity of the cable conductors under single-shot conditions, an action of $259 \times 10^{6} A^{2} s$ (2.2 times the action for nine shots) was assumed and resulted in a $89.1^{\circ} \mathrm{C}$ temperature rise. This corresponds to a cable peak current of $300 \mathrm{kA}$ over $2.9 \mathrm{~ms}$.

A high frequency current-sheet numerical analysis of the geometry was performed to estimate cable inductance and repulsion loads acting on the conductors. This analysis predicted the cable inductance to be $123 \mathrm{nH} / \mathrm{m}$ with a repulsion force of $71.5 \mathrm{kN} / \mathrm{m}$ (408 $\mathrm{b} / \mathrm{in}$ ) acting on each primary conductor at a current of $100 \mathrm{kA}$ per primary ( $300 \mathrm{kA}$ total). The resultant hoop load applied to the fiber over-wrap was estimated at $143 \mathrm{kn} / \mathrm{m}(816 \mathrm{lb} / \mathrm{in})$. At $22.2 \mathrm{kA}$ per primary, the load would be approximately $5 \%$ of these values.

The selected hexapolar design consists of six primary conductors, each consisting of 3,192 strands $(19 \times 7 \times 24)$ of 36 A.W.G tinned copper wire yielding a copper cross sectional area of $0.404 \mathrm{~cm}^{2}\left(0.063 \mathrm{in}^{2}\right)$. DC electrical resistance for each primary is $426 \mu \Omega / \mathrm{m}$ resulting in a cable resistance of $142 \mu \Omega / \mathrm{m}$ per polarity. A $2 \mathrm{~mm}$ (0.08 in) thick SILASTIC WC-70® silicone rubber insulation layer is extruded over the primary conductor, is rated at a maximum operating temperature of $200^{\circ} \mathrm{C}$ and has a dielectric strength of $21,654 \mathrm{~V} / \mathrm{mm}(550 \mathrm{~V} / \mathrm{mil})$. The silicone insulation on the positive and negative primary conductors is color coded red and blue, respectively, for ready identification of conductor polarity. The 


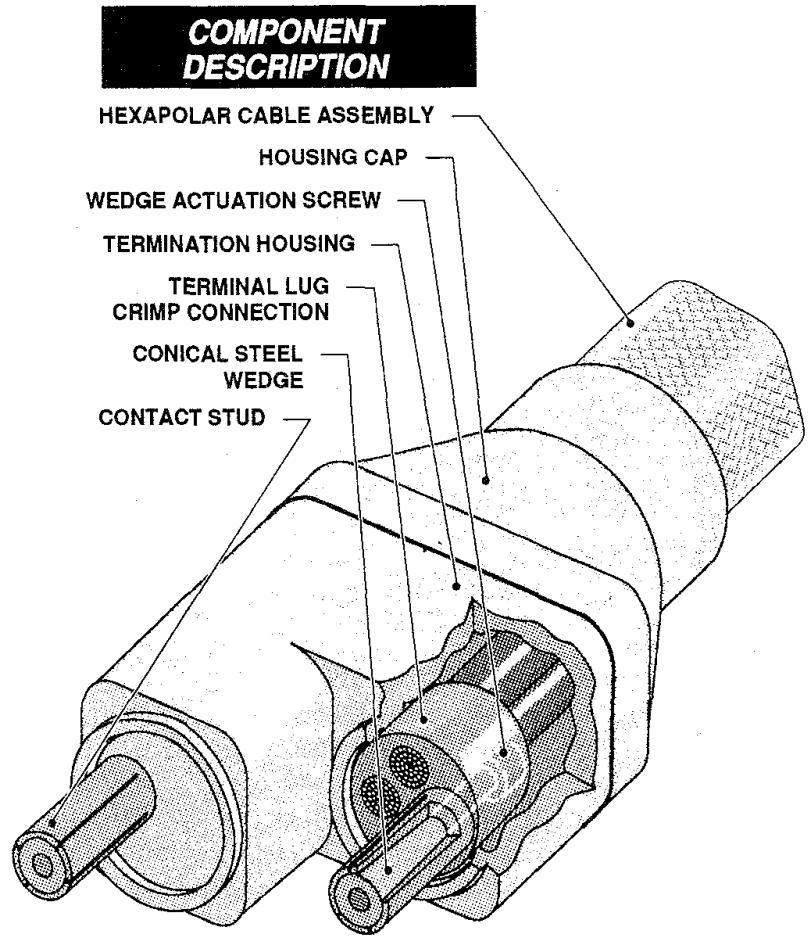

Figure 2. Standardized Modular Termination

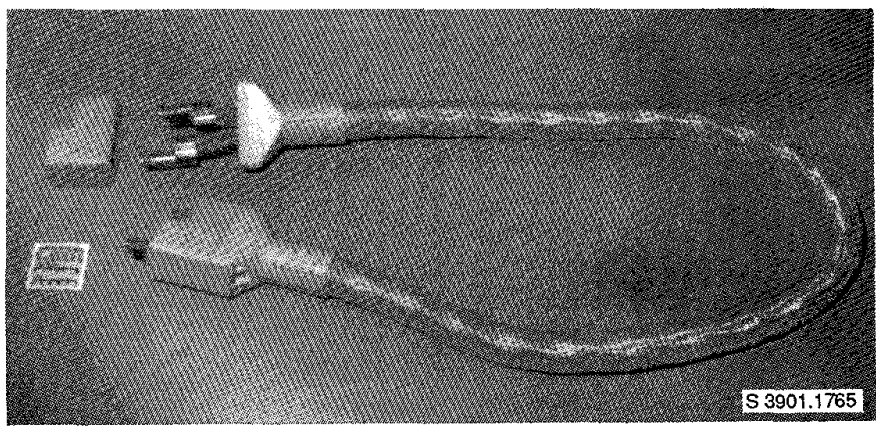

Figure 3. Completed prototype cable and termination assembly

primary conductors are helically wound around the fiber core on a $0.36 \mathrm{~m}$ (14 in) pitch to obtain maximum cable flexibility. The $50 \%$ KEVLAR $B 29,50 \%$ fiberglass stranded core serves two purposes; maintain the cable in its hexapolar configuration and provide axial strain relief of the cable under magnetic/mechanical loading. A $0.08 \mathrm{~mm}(0.003 \mathrm{in})$ thick E-124-3 TEFLON® tape is half-lap-wrapped around the primary conductor and fiber core assembly as a secondary insulation barrier. Dielectric strength for the TEFLON tape is $10,500 \mathrm{~V}$ at a rated operating temperature of -73 to $260^{\circ} \mathrm{C}$. Finally, a $0.9 \mathrm{~mm}(0.035 \mathrm{in})$ thick KEVLAR 29 fiber covering is braided over the assembly, at a braid angle of $76^{\circ}$ for an effective coverage of over $95 \%$. This covering is designed to support electrical repulsion loads transverse to the cable axis of up to $14.7 \times 10^{6} \mathrm{~N} / \mathrm{m}(84,000 \mathrm{lb} / \mathrm{in})$ as well as serve as a flame and abrasion resistant shield.

Two cable manufacturers have been identified and qualified for fabrication of the hexapolar cable assembly. They are New England Electric Wire Corporation, Lisbon, $\mathrm{NH}$ and Specialty Cable Corporation, Wallingford, CT. Upon completion of the cable design, approximately $30 \mathrm{~m}$ of fully assembled hexapolar flexible cabling was purchased for prototype testing and design parameter validation.

\section{MODULAR TERMINATION DESIGN}

Standardized modular cable terminations (fig. 2) are being developed in conjunction with the hexapolar cable. These terminations feature compact construction, small footprint, a unique single-bolt (per polarity) high contact area/pressure electrical terminal, and electromagnetically self supporting high voltage insulated casing. The cable termination mates to a simply machined receptacle. The termination consists of three major components; terminal lug, termination housing and housing cap.

The terminal lug is constructed from monolithic copper material stock and serves two purposes; to permanently connect primary cables of like polarity and to provide a reliable, mechanically actuated high current electrical contact that occupies minimum volume. The contact stud of the terminal has a cylindrical outside surface and a conical inner surface. This section is axially split into four $90^{\circ}$ segments. A conical steel wedge mates to the inner surface of the contact stud, has a steel roll pin that keys into one of the axial spaces between the segments, and is threaded to accept an actuation screw. When the actuation screw is tightened, the conical surface of the wedge acts to amplify the axial load in the screw into a high transverse load clamping the outer contact surface into a cylindrical copper receptacle. By applying the recommended seating torque of $258 \mathrm{Nm}(190 \mathrm{ft}-\mathrm{b})$ to the $8 \mathrm{~mm}(5 / 16 \mathrm{in})$ diameter socket head cap screw, a contact pressure of over $68.9 \mathrm{MPa}\left(10,000 \mathrm{lb} / \mathrm{in}^{2}\right)$ is developed. The contact has a total surface area of $19 \mathrm{~cm}^{2}$ $\left(2.95 \mathrm{in}^{2}\right)$ At a design allowable of $15 \mathrm{kA} / \mathrm{cm}^{2}\left(100 \mathrm{kA} / \mathrm{in}^{2}\right)$, it can withstand a peak current of approximately $300 \mathrm{kA}$. The bulk of the terminal lug consists of the primary conductor crimp connections. Three cylindrical holes are thru-drilled in the lug wherein bare sections of the primary conductors are inserted. After insertion, a $1 \mathrm{~cm}(0.4 \mathrm{in})$. diameter cylindrical indenter is used to crimp the conductor into place at a load force of $67 \mathrm{kN}(15,000 \mathrm{lb})$. The crimping load force was determined by testing several indenter sizes and load force combinations until a combination was found where the primary conductor failed in tension rather than pulling the conductor from the crimp joint.

Mechanical support and insulation of the single bolt expanding terminal lugs is achieved using the termination housing and housing cap. The housing and cap are made of $20 \%$ glass filled nylon which has the desirable combination of mechanical strength, toughness and good dielectric strength. The terminal lugs are secured to the housing with snap rings while cable strain relief is achieved using two aircraft band clamps around the neck of the housing cap. In the transition region from the hexapolar arrangement to two discrete polarities, the cables are not magnetically compensated and must be mechanically supported. Support is achieved by filling the voids around the cables using a compliant, castable polyurethane. The polyurethane supports the cable but is flexible enough to allow for easy alignment and installation of the expanding copper studs into their receptacles. An additional feature of the terminal housing is that it positions the terminals at different axial locations with respect to the cable. This serves two purposes. First, it provides voltage isolation and line-ofsight blocking between the terminals. Secondly, it prevents connection of the cable terminals to the wrong polarity. Figure 3 is a photograph of a completed prototype cable and termination assembly. It shows a fully assembled termination on one end of the cable and the terminal lugs with the termination housing removed on the other end. 


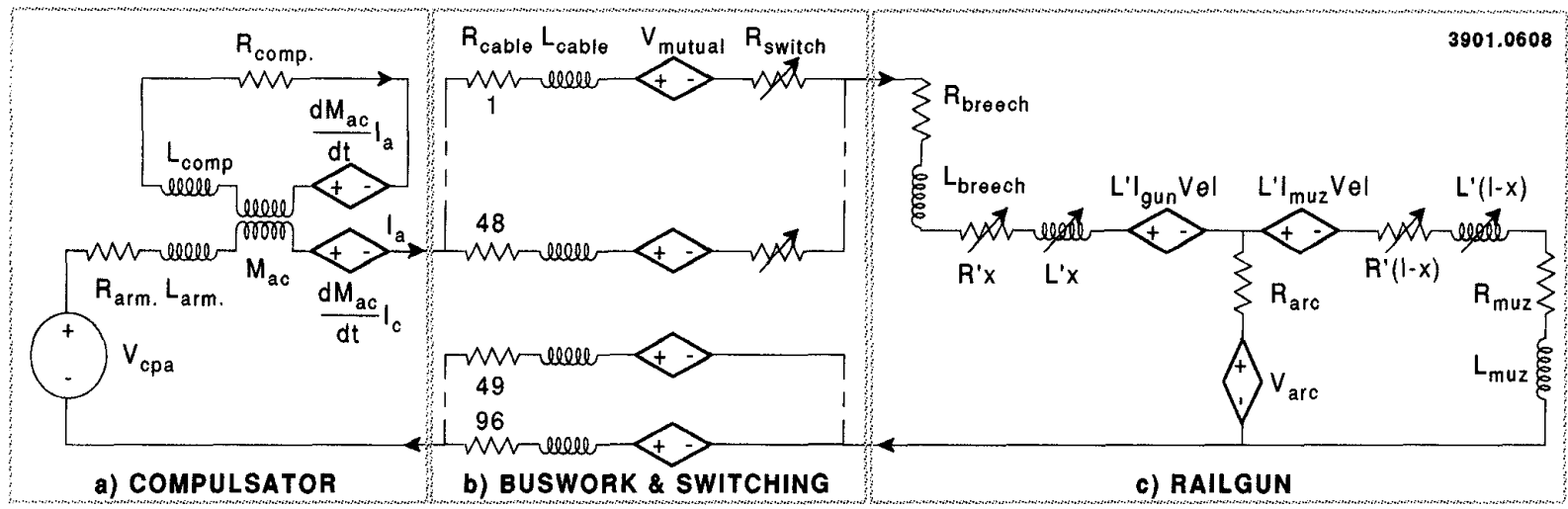

Figure 4. Lumped-parameter circuit model for the Range Gun bus simulation

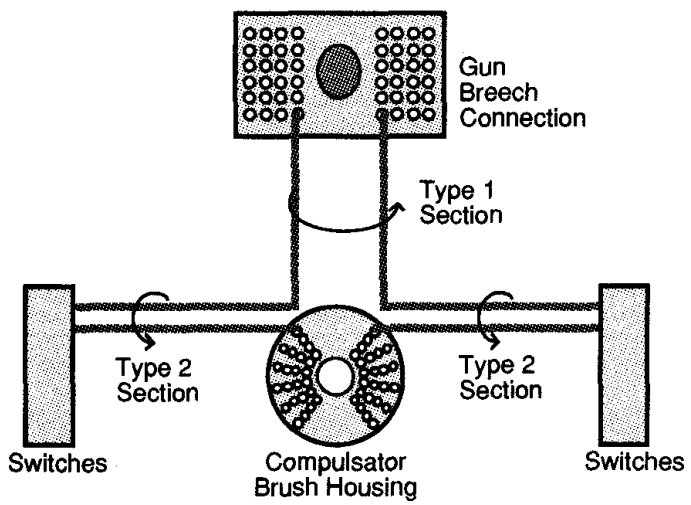

a) Physical Layout

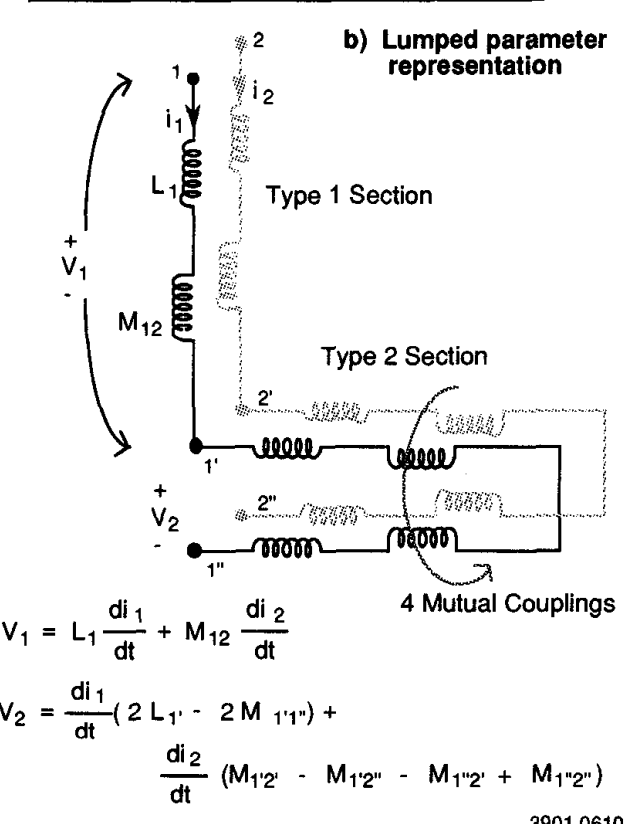

Figure 5. Gun bus cable arrangement used to determine mutual inductance values for the simulation
The receptacle for the termination entails two fabrication requirements; the connections must be located in two parallel planes corresponding to the axial separation between terminal lugs and the two cylindrical connection holes must be drilled and reamed parallel to each other and at the same center line spacing as the terminal lugs.

\section{CABLE PARALLEL OPERATION SIMULATION}

A numerical simulation was developed to predict the behavior of the range gun system under ideal and randomized circuit parameters and models the complete energy transfer process from kinetic energy in the compulsator rotor to electromagnetic energy stored in the discharge circuit to kinetic energy in the launch package. One-hundred and twelve state variables are used including ninety-six elements to model inductive interaction of the flexible cable gun bus and solid state switch modules.

The compulsator section of the model (fig. 4a) has primary inputs of initial angular velocity of the rotor, angular position of the rotor at switch firing, and percent excitation of the field coil. Rotor torque is calculated and used with the moment of inertia of the rotor to determine the energy transfer from the compulsator. Mutual inductance coupling between the compulsator armature winding and the compensating winding is also modeled.

Samples of the prototype flexible gun bus cables were measured to determine cable conductor self and mutual coupling effects and produce a mutual inductance curve as a function of distance between cables. The cables are arranged in two, four-bysix rectangular arrays (fig. 5) in which each cable travels between the compulsator terminals, a bank of switch modules and then to the breech of the gun. For simulation purposes the cable path was broken in to two types of straight, parallel sections. "Type One" sections represent the two groups of cables running parallel to each other at a fixed distance apart and "Type Two" sections represent the group running to the switches. The simulation accepts as inputs cable spacings and lengths as well as allowing a percentage of variation in the cable spacing and lengths to be specified. To simulate less than ideal conditions, parameter variations within an allowable percentage are computed by the simulation and conform to a uniform random distribution.

Initially, the switch modules (fig. 4b) are modeled using a maximum resistance until the generator discharge is initiated and then transition through a switching period before settling at their final 


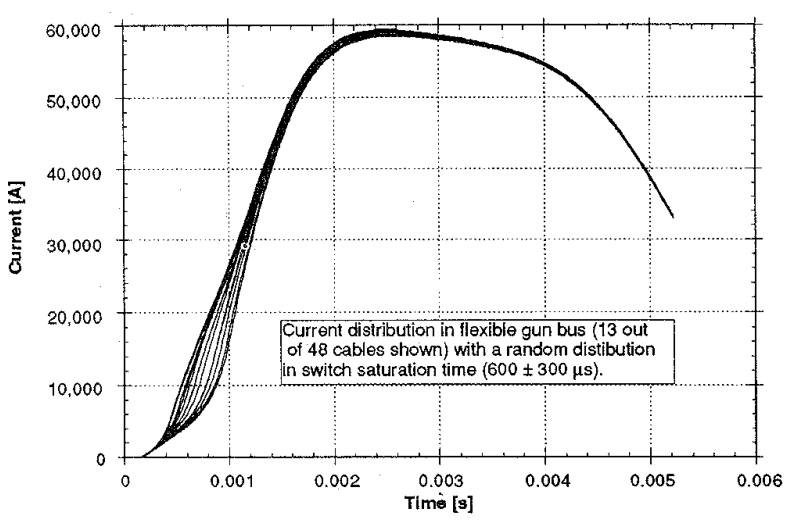

Figure 6. Simulation results for a $\pm 50 \%$ variation in switch saturation time showing current in thirteen of the 48 paths

minimum resistance. Switch resistance, timing, and percent variation of switch timing is accepted as an input to the simulation as well. A designated switch or group of switches can also be forced to fail to fire to evaluate discharge fault modes.

The gun section of the model (fig. $4 \mathrm{c}$ ) has primary inputs of launch package mass, gun length, and muzzle resistance (muzzle arc suppressor). A high muzzle resistance has been used to date, with the intent to investigate this parameter later. Position and velocity of the launch package are two of the state variables and dependent voltage sources are used to represent the energy consumed by acceleration of the launch package and electromagnetic energy stored in the gun (from the breech to the armature). A velocity dependent armature voltage is included and is based upon examination of data accumulated from the Task $B$ program[7]. Armature voltage remains low until it reaches a velocity of $1,000 \mathrm{~m} / \mathrm{s}$, rises linearly to 600 volts at $2,000 \mathrm{~m} / \mathrm{s}$, remaining constant thereafter.

For example, a typical simulation without random parameter variations was run with the compulsator at full rotor speed and full excitation field launching a $2.0 \mathrm{~kg}$ package. This resulted in a peak current of 2.83 MA being delivered to the gun armature, an acceleration time is $5.09 \mathrm{~ms}$, peak launch package velocity of 3,285 $\mathrm{m} / \mathrm{s}$ yielding $10.791 \mathrm{MJ}$ of package kinetic energy. The compulsator rotor droops from its initial angular velocity of 7,500 $\mathrm{pm}$ to $6,783 \mathrm{rpm}$ at projectile exit.

Under these conditions, with all of the primary conductor lengths identical and all of the switches following the same resistance curve; forward conductor currents remain equal throughout the simulation and reach a peak of $59.0 \mathrm{kA}$ per cable. The return currents remain equal and opposite to the forward currents at all times, therefore indicating that all mutual inductance effects are cancelled.

Effects of $a \pm 50 \%$ variation in the switch (thyristor) saturation times is shown in figure 6 . The cable currents diverge during the switching event but converge as the simulation continues. Little effect on overall system performance is experienced. $A \pm 10 \%$ variation in cable lengths $( \pm 80 \mathrm{~cm})$ forces the cable currents to distributed over a range of 55.2 to $63.5 \mathrm{kA}$, a deviation of $7.6 \%$ from the nominal value of $59.0 \mathrm{kA}$. It should be noted that actual cable length will be controlled to within less than $1 \%$.
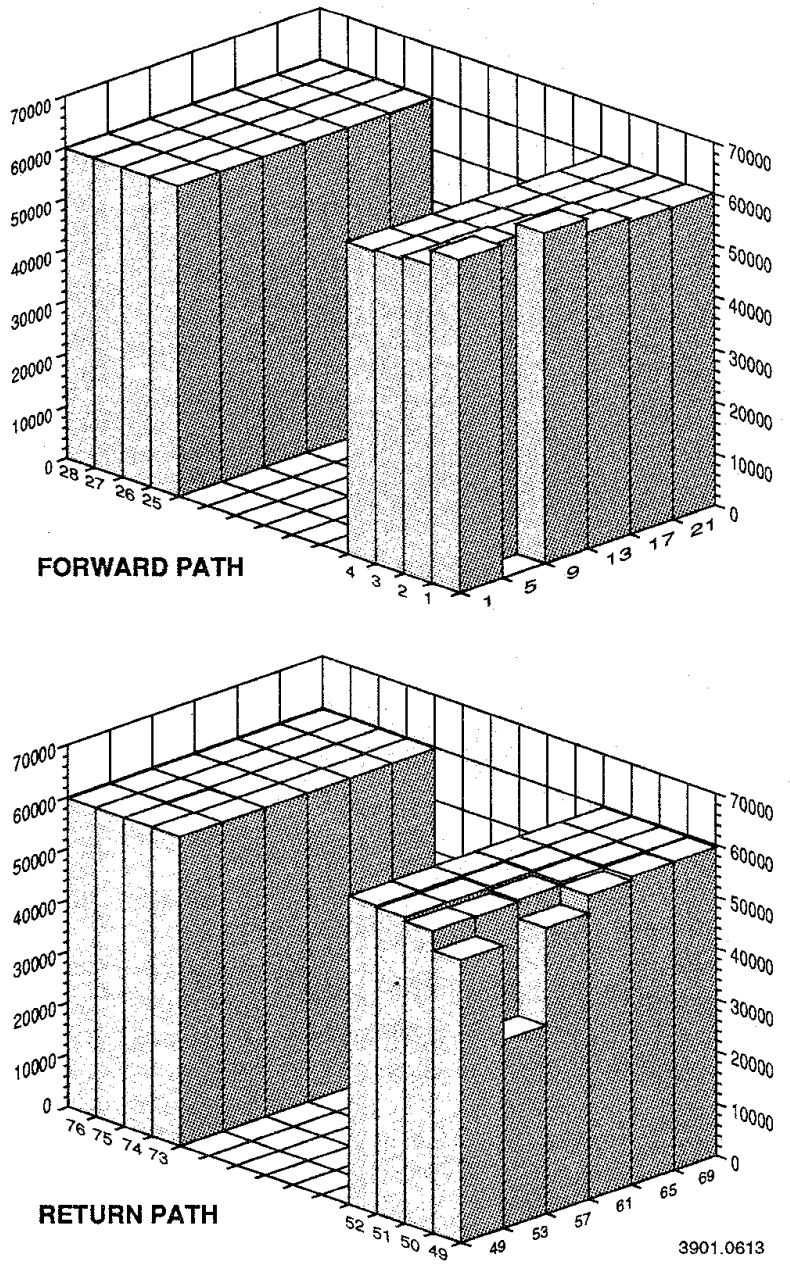

Figure 7. Simulation results for a single switch (\#5) not flring showing current in each of the 48 paths

Asymmetric current distribution effects of a nonfiring switch are shown in figure 7 . While no current flows in the open-circuited forward path of element 5 , current still flows in its return path, element 53. This perturbs the previously discussed mutual inductance cancellation and the neighboring cables carry more forward current. The average current increases to $59.9 \mathrm{kA}$ and the highest current is $64.9 \mathrm{kA}$, a deviation of $9.99 \%$ from the nominal value of $59.0 \mathrm{kA}$, or a $8.26 \%$ deviation from the average value.

These preliminary results show relative insensitivity to the actual switching transient (saturation time), but indicate that close attention must be paid to controlling cable lengths as well as the inductance of the components they are connected to. A single nonfiring switch does not appear to cause a significant problem, but the case where several switches fail to fire must be investigated. It is anticipated that for shots below full-energy, the failure of several switch modules may be tolerated.

\section{CABLE \& TERMINATION TEST RESULTS}

A $3 \mathrm{~m}$ section of the primary conductor and fully assembled cable were tested under high voltage static conditions. Primary cable insulation was tested by coiling a bare copper wire around the circumference of the silicone insulating jacket and connecting an end 
Table 1. Cable termination temperature rise vs action.

\begin{tabular}{|c|c|c|c|}
\hline & $\begin{array}{c}\text { Total Action } \\
{\left[\mathrm{A}^{2} \mathrm{~s}\right]}\end{array}$ & $\begin{array}{c}\text { Cable } \Delta \mathrm{T} \\
{\left[{ }^{\circ} \mathrm{C}\right]}\end{array}$ & $\begin{array}{c}\text { Stud } \Delta T \\
{\left[{ }^{\circ} \mathrm{C}\right]}\end{array}$ \\
\hline 1 & $17 \times 10^{6}$ & 1.8 & 0.3 \\
\hline 2 & $80 \times 10^{6}$ & 11.7 & 2.2 \\
\hline 3 & $140 \times 10^{6}$ & 21.7 & 8.3 \\
\hline 4 & $320 \times 10^{6}$ & 85.6 & 12.2 \\
\hline
\end{tabular}

of the wire to one polarity of a $30 \mathrm{kV}$ power supply while the other terminal was connected to the primary conductor. Test voltage was increased up to the power supply limit of $30 \mathrm{kV}$ without experiencing breakdown in insulation integrity. Subsequently, the cable assembly was tested. Like polarities of the primary conductors were connected together and electrically isolated at the conductor ends with a MYLAR(B) insulation barrier. Opposite polarities were connected to the power supply and also tested to $30 \mathrm{kV}$ without breakdown. High frequency $(100 \mathrm{kHz})$ measurements of the cable assembly gave a cable resistance of $136 \mu \Omega / \mathrm{m} /$ polarity and an inductance of $139 \mathrm{nH} / \mathrm{m}$.

Following mechanical testing of the terminal lug crimp joints, a series of D.C. electrical tests were performed to verify the electrical and thermal properties of the cable and termination design. Using a 6000 A D.C. power supply, a series of resistive heating tests were conducted on an assembly consisting of two terminal lugs with three primary conductors crimped into. place. Table 1 shows the temperature rise of the cable and stud as a function of total action. In addition, the voltage drop across the crimp joint and the split copper stud were measured. Using this data, a D.C. contact resistance was derived for the cable termination:

$$
\begin{aligned}
& \text { - Crimp Joint Contact Resistance ..................... } 2.2 \mu \Omega \\
& \text { - Split Stud Contact Resistance....................... } 2.6 \mu \Omega \\
& \text { - Total Termination Resistance ....................... } 4.8 \mu \Omega
\end{aligned}
$$

It is important to note that this total termination resistance is distributed over the length of the crimp joint and terminal lug, which is $0.051 \mathrm{~m}$ in length. This yields a resistance of $95 \mu \Omega / \mathrm{m}$, which is lower than the bulk resistance of the cable polarity.

In addition a thermal fatigue test of the above assembly was conducted and consisted of 100 shots at an action of $17 \times 10^{6} \mathrm{~A}^{2} \mathrm{~s}$. The contact resistances were monitored for any appreciable change over time. After 100 shots, the total termination resistance had increased $5 \%$.

\section{CONCLUSIONS}

With the hexapolar flexible cable and terminations, design goals for a 3.2 MA high current bus have been satisfied. High flexibility, low inductance, low resistance, high temperature operation and low cost have been achieved. In addition, this design may be scaled up to at least three times the net conductor cross sectional area without exceeding manufacturing limitations.

At the time of this writing, high-current testing of the cable assembly has not been performed. Fabrication of the majority of components required to test the cable with an on-site capacitor bank has been completed in preparation for these tests. Full-current test data will be published as soon as available.

\section{ACKNOWLEDGMENTS}

Funding for the work discussed in this publication has been provided by the Defense Advanced Research Projects Agency and the U. S. Army under contract number DAAA21-86-C-0281. The authors also appreciate the contributions from Bob Meserve, Mac McKenzie and Clifford Bovin of New England Electric Wire Corporation, Lisbon, $\mathrm{NH}$ as well as Louis Caruso of Specialty Cable Corporation, Wallingford, CT for their suggestions on cable material selections and help on cable fabrication specifications.

\section{REFERENCES}

[1] W. A. Walls, et al., "A Field Based, Self-Excited Compulsator Power Supply for a 9 MJ Railgun Demonstrator," IEEE Transactions on Magnetics, vol 27, no. 1, January 1991, pp 335-340.

[2] W. A. Walls, et al., "Design of a Self-Excited, Air-Core Compulsator for a Skid Mounted, Repetitive Fire 9 MJ Railgun System," IEEE Iransactions on Magnetics, vol 25, no. 1, January 1989, pp 574-579.

[3] J. J. Hahne and R. C. Zowarka, "High Current, High Voltage Bus Design," presented at the 8th IEEE Pulsed Power Conference, San Diego, CA, June 17-19, 1991.

[4] R. A. Thelen and J. H. Price, "Power Electronics in the 9 MJ Range Gun System," presented at the 8th IEEE Pulsed Power Conference, San Diego, CA, June 17-19, 1991.

[5] Product brochure 7/79-A1, Flex-Cable Division, FLX Corporation, 1875 Stephenson Highway, Troy, Michigan 48084, (313) 689-4666

[6] K. A. Jamison, et al., "High Energy Cable Development for Pulsed Power Applications," IEEE Transactions on Magnetics, vol 27, no. 1 January 1991, pp 374-379.

[7] J. H. Price and M. W. Ingram, "Large and Small Caliber Solid Armatures: Experimental Results," IEEE Transactions on Magnetics, vol 27, no. 1, January 1991, pp 245-247. 